\title{
纳米酶：对抗细菌的新策略
}

\author{
傅佳骏 $^{1}$, 沈 涛 $^{1}$, 吴 佳 $^{2}$, 王 成 ${ }^{1}$ \\ (1. 南京理工大学 化工学院, 南京 210094; 2. 江苏中烟技术中心, 南京 210009)
}

\begin{abstract}
摘 要: 由细菌引发的相关疾病和环境污染等问题引起了人们的高度重视, 同时随着抗生素的使用, 细菌的耐药性 逐渐增强, 人们急需开发新型抗菌剂。诸如溶菌酶、髓过氧化物酶等天然酶具有显著的抗菌能力, 但其作为抗菌剂 存在保质期短、生产成本高等缺点, 很难大规模生产。因此, 人们正探索寻求天然酶的替代品。纳米酶是新一代人工 模拟酶, 兼具纳米材料独特的理化性质和类酶催化活性, 因其结构稳定、生产成本低等优点受到广泛关注。本文综 述了纳米酶的抗菌机制和近期抗菌纳米酶的主要研究进展, 并对未来该领域的研究进行展望。
\end{abstract}

关 键 词: 纳米酶; 过氧化物酶; 氧化物酶; 卤代过氧化物酶; 脱氧核糖核酸酶; 抗菌; 综述 中图分类号: Q811 文献标识码: A

\section{Nanozyme: a New Strategy Combating Bacteria}

\author{
FU Jiajun ${ }^{1}$, SHEN Tao ${ }^{1}$, WU Jia ${ }^{2}$, WANG Chen ${ }^{1}$
}

(1. School of Chemical Engineering, Nanjing University of Science and Technology, Nanjing 210094, China; 2. Jiangsu China Tobacco Technology Center, Nanjing 210009, China)

\begin{abstract}
Bacteria-related diseases, environmental pollution and other issues have attracted enough attention. Meanwhile, with the use of antibiotics, bacteria evolved strong drug resistance forcing people to develop new antibacterial agents urgently. Natural enzymes such as lysozyme and myeloperoxidase have significant antibacterial ability. However, natural enzymes own limitations such as short shelf life and high production costs. Besides, they are difficult in applying to large-scale production. Therefore, people are seeking alternatives to natural enzymes. Nanozymes are a new generation of artificial enzymes which have unique physical and chemical properties of nanomaterials and enzyme-like catalytic activity. Because of structural stability and low production cost, they are widely explored. This article reviews the antimicrobial mechanism and the recent progress of nanozymes in antibacterial research, and, finally, gives some prospects for future research.
\end{abstract}

Key words: nanozyme; peroxidase; oxidase; haloperoxidase; deoxyribonuclease; antibacterial; review

细菌感染引起的相关疾病严重威胁着人类的健 康 $^{[1]}$, 抗生素作为对抗细菌的常用化学试剂已广泛 应用于人类生活中。然而, 由于抗生素的滥用, 细菌 逐渐产生耐药性, 降低了抗菌效果, 导致了更高的 死亡率。更为严重的是，当细菌附着于基质表面时 易形成生物膜, 构成与外界物质交换的屏障, 阻碍
了抗生素的渗透, 进一步增加了抗菌难度 ${ }^{[2]}$ 。目前, 细菌生物膜的形成已对植入型医疗设备、海洋设备 等造成了严重影响 ${ }^{[3-4]}$ 。因此, 在避免产生细菌耐药 性的同时，探索高效杀菌的新型抗菌剂十分必要。

2007 年, Yan 等 ${ }^{[5]}$ 首次发现四氧化三铁磁性纳米 粒子 $\left(\mathrm{Fe}_{3} \mathrm{O}_{4} \mathrm{MNPs}\right)$ 具有本征的类过氧化物酶活性,

收稿日期: 2020-05-18; 收到修改稿日期：2020-07-24; 网络出版日期：2020-08-28

基金项目: 国家自然科学基金(U1737105, 51672133) National Natural Science Foundation of China (U1737105, 51672133)

作者简介：傅佳骏(1980-), 男, 教授.E-mail: fujiajun668@njust.edu.cn FU Jiajun(1980-), male, professor. E-mail: fujiajun668@njust.edu.cn 
能够催化双氧水 $\left(\mathrm{H}_{2} \mathrm{O}_{2}\right)$ 氧化过氧化酶底物四甲基联 苯胺 $(\mathrm{TMB}) 、$ 邻苯二胺 $(\mathrm{OPD})$ 和二氨基联苯胺(DAB), 从酶学角度系统研究了纳米材料的酶学特性, 建立 了相应测定标准, 并将其作为酶的替代品 ${ }^{[6]}$ 。2013 年, Wei 等 ${ }^{[7]}$ 将这类纳米材料模拟酶定义为纳米酶。 纳米酶是新一代人工模拟酶, 兼具纳米材料独特的 理化性质和类酶催化活性, 在生理条件下能够催化 天然酶的底物并遵循类似的酶促反应动力学。这种 类酶催化活性来自纳米酶自身所具有的特殊纳米结 构, 无需额外引入催化功能基团或者天然酶 ${ }^{[8]}$ 。相对 于天然酶和其他人工模拟酶, 纳米酶的稳定性 更好、成本更低并且催化活性可调 ${ }^{[9-10]}$ 。研究人员 从天然酶抗菌(溶菌酶、髓过氧化物酶等)中得到启 示 $^{[11-13]}$, 将纳米酶的应用拓展到抗菌领域。与传统 抗生素相比, 利用纳米酶抗菌具有广谱性和耐用性 等优点。

本文简要介绍了以过氧化物酶、氧化酶、卤代 过氧化物酶和脱氧核糖核酸酶为模型的纳米酶及其 相应的抗菌机制, 并就近期纳米酶在抗菌应用方面 的研究进展作了综述。

\section{1 过氧化物酶型}

过氧化物酶(Peroxidase, POD)是一类催化过氧 化氢 $\left(\mathrm{H}_{2} \mathrm{O}_{2}\right)$ 分解反应的含铁血红素酶 ${ }^{[14]}$, 主要为辣 根过氧化物酶(Horseradish peroxidase, HRP), 在废 水处理、环境化学、生物传感、有机合成中都有较 多的应用 ${ }^{[15]}$ 。此外, HRP 还参与了生命体系许多重 要的氧化还原反应 ${ }^{[16]}$ 。自 2007 年首次报道 $\mathrm{Fe}_{3} \mathrm{O}_{4} \mathrm{MNPs}$ 具有类过氧化物酶活性后, 其他具有这种类酶活性 的纳米酶陆续被发现, 纳米酶的应用研究也拓宽到 了包括抗菌在内的生物、医学、环境治理等领域 ${ }^{[17-19]}$ 。

过氧化物酶能够催化 $\mathrm{H}_{2} \mathrm{O}_{2}$ 的分解, 产生具有强 氧化性的羟基自由基 $(\cdot \mathrm{OH}) \circ \cdot \mathrm{OH}$ 是最具破坏性的活 性氧(Reactive oxygen species, ROS)之一, 可分解核 酸、蛋白质、多糖等细菌生物膜成分, 破坏细菌的 物质结构, 导致其死亡 ${ }^{[20]}$ 。一般来说, $\mathrm{H}_{2} \mathrm{O}_{2}$ 应用于 杀菌时往往需要较高的浓度, 而高浓度的 $\mathrm{H}_{2} \mathrm{O}_{2}$ 对 正常生理组织同样具有破坏作用 ${ }^{[21]}$ 。基于此, 具有 类过氧化物酶活性的纳米酶, 可以有效借助其类酶 活性催化 $\mathrm{H}_{2} \mathrm{O}_{2}$ 产生・OH, 充分提高低浓度 $\mathrm{H}_{2} \mathrm{O}_{2}$ 时 的杀菌效率, 或者对单独使用 $\mathrm{H}_{2} \mathrm{O}_{2}$ 无法杀死的耐 药菌进行杀灭。在这方面, 具有类过氧化物酶活性 的纳米酶由于它们对 $\mathrm{H}_{2} \mathrm{O}_{2}$ 抗菌性能的促进作用而 避免了高浓度 $\mathrm{H}_{2} \mathrm{O}_{2}$ 引起的损伤, 因此大大促进了
人们对于纳米酶抗菌应用的探索。然而, 这类纳米 酶即使对 $\mathrm{H}_{2} \mathrm{O}_{2}$ 浓度要求很低, 仍然需要 $\mathrm{H}_{2} \mathrm{O}_{2}$ 在酸 性环境中才能启动其催化作用。此外, 使用不同类 过氧化物酶活性的纳米酶抗菌时, 对 $\mathrm{H}_{2} \mathrm{O}_{2}$ 浓度的 要求不尽相同, 将其应用于抗菌尚无确切的标准。综 上, 将此类纳米酶应用于实际生活还需进一步研究。

\section{2 氧化酶型}

氧化酶(Oxidase, OXD)是一类催化氧化还原反 应的重要酶类制剂。对于氧化酶催化的反应，其底 物被分子氧 $\left(\mathrm{O}_{2}\right)$ 氧化, 转化为水或 $\mathrm{H}_{2} \mathrm{O}_{2}$ (在某些特 定情况下可转化为超氧自由基 $\left.\mathrm{O}_{2}{ }^{-{ }^{-}}\right)^{[22]}$ 。

具有类氧化酶活性的纳米酶主要应用于两个方 面：1)对于某些底物在催化过程中具有的特征性变 化(如氧化导致的颜色变化), 使其成为检测的理想 试剂 ${ }^{[23-24]} ; 2$ )在催化过程中同时产生的 $\mathrm{H}_{2} \mathrm{O}_{2} 、 \mathrm{O}_{2}{ }^{--}$ 等活性自由基，可提供抗菌等应用的新思路。 $\mathrm{H}_{2} \mathrm{O}_{2}$ 和 $\mathrm{O}_{2}{ }^{--}$由于其强氧化性可直接氧化细菌外层结构, 破坏细胞的通透性屏障, 导致细菌内外物质的电化 学平衡失衡, 致使细菌死亡 ${ }^{[25]}$ 。同样, $\mathrm{O}_{2}{ }^{--}$可直接与 核酸、蛋白质等发生反应, 致细菌死亡。

针对大部分产生 ROS 的纳米酶, 考虑到生物相 容性问题, 通常情况下 ROS 在生理条件下需维持稳 定的水平, 保持稳态平衡。这种平衡一旦被打破, 容 易引起疾病。因此, 纳米酶在生理环境下的催化产 POS 水平需要得到量化。

\section{3 卤代过氧化物酶型}

卤代过氧化物酶(Haloperoxidase, HPO)是一种 参与卤化反应的卤化酶 ${ }^{[26]}, 1959$ 年, 由 Hager 等 ${ }^{[27]}$ 研究卡尔里霉素的天然生物来源时, 在真菌 Calderiomyces fumago 体内发现, 它广泛存在于海 洋高等植物、哺乳动物、藻类、微生物中。根据 卤素离子电负性的不同, 可分为氯过氧化物酶、溴 过氧化物酶和碘过氧化物酶。根据辅基的不同,可分 为亚铁血红素卤代过氧化物酶、钒卤代过氧化物 酶和不含辅基的卤代过氧化物酶 ${ }^{[28]}$ 。其中, 以钒卤 代过氧化物酶的研究最为深入, 可在 $\mathrm{H}_{2} \mathrm{O}_{2}$ 条件下 催化卤素离子产生次卤酸( $\mathrm{HOX})$, 并在后续形成单 线态氧 $\left({ }^{1} \mathrm{O}_{2}\right)$ 。 $\mathrm{HOX}$ 和 ${ }^{1} \mathrm{O}_{2}$ 均具有很强的抗菌活性。 图 1 揭示了含有卤代过氧化物酶的防污装置, 利用 环境中的卤素离子和 $\mathrm{H}_{2} \mathrm{O}_{2}$ 产生 HOX 的防污杀菌的 原理 ${ }^{[29]}$ 。 


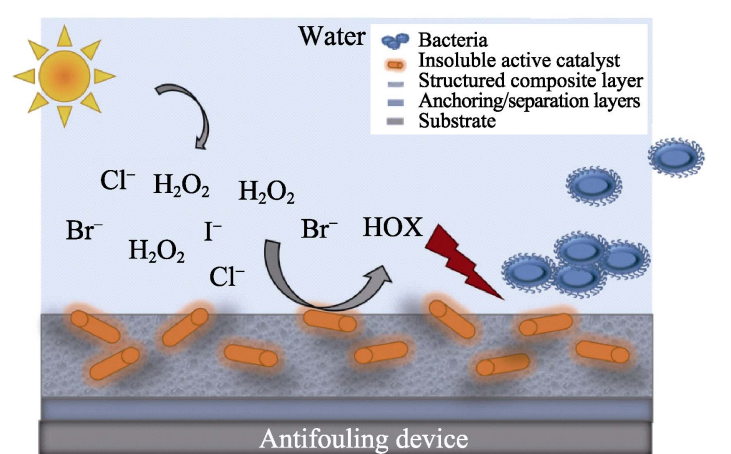

图 1 含有类卤代过氧化物酶活性的防污装置中活性物质的 工作机理 ${ }^{[29]}$

Fig. 1 Principle of active substances incorporated in an antifouling device with haloperoxidase-like activity ${ }^{[29]}$

基于文献 ${ }^{[30]}$ 报道，卤化反应中的卤化剂和氧化 剂很容易扩散透过大肠杆菌(Escherichia coli)等细 菌的细胞膜, 从而杀灭细菌。近年来, 研究人员发现 细菌群体感应(Quorum sensing, QS)系统是细菌生物 膜形成的重要影响因素之一 ${ }^{[31]}$ 。1994 年由 Fuqua ${ }^{[29,32]}$ 首次发现, QS 是细菌根据特定信号分子(Atoinducer, $\mathrm{AI})$ 的浓度来检测周围环境中自身或其他细菌的数 量变化, 启动体内相关基因的表达以适应环境变化 的调控系统(图 2)。通过卤化降解信号分子干扰这种 QS 系统, 细菌将失去形成组织生物膜的能力。此类 抗菌模式已成为研究的热点方向 ${ }^{[33-34]}$ 。

\section{4 脱氧核糖核酸酶型}

脱氧核糖核酸酶(Deoxyribonuclease, DNase), 是一类能够切割降解 DNA 分子且没有序列识别特 异性的核酸酶, 按照切割 DNA 的特点, 可分为 DNase I 和 II。其中 DNase II 广泛分布于哺乳动 物的组织中 ${ }^{[35]}$ 。该种酶类制剂常运用于呼吸系统感 染的治疗 ${ }^{[36]}$ 。近年来, 具有类 DNase 活性的人工核 酸酶, 多为 $\mathrm{Zn}(\mathrm{II}) 、 \mathrm{Ce}(\mathrm{IV}) 、 \mathrm{Cu}(\mathrm{II})$ 基金属配合物材 料 ${ }^{[37-39]}$, 受到了广泛关注。

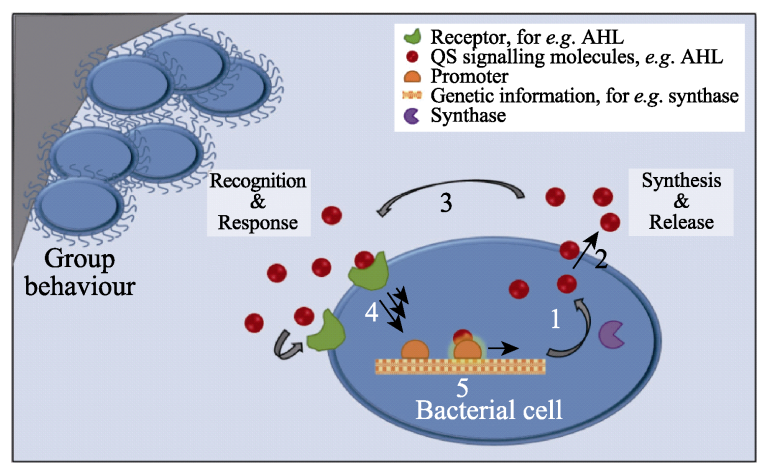

图 2 信号分子对海洋细菌 QS 系统的调节机制[29]

Fig. 2 Regulation mechanism of signaling molecules on marine bacterial QS system ${ }^{[29]}$

AHL: Acylated homoserine lactones
在生物膜中，微生物通过自身合成的细胞外基 质-聚合物一底物(Extracellular-polymeric-substances, EPS)结合在一起, 这些物质通常由多糖、蛋白质和胞 外 DNA(Extracellular DNA, eDNA)组成 ${ }^{[40]}$ 。如图 3(a) 所示, eDNA 既是细胞与细胞之间的互连体, 又是将 细菌与底物表面或其他 EPS 成分相联的桥梁 ${ }^{[41]}$ 。一旦 eDNA 遭到破坏, 生物膜就很容易被去除。而 DNase 能够靶向降解这种 EPS 中的关键组分, 从而有效抑 制生物膜形成(如图 3(b))。

\section{5 纳米酶抗菌应用}

\section{1 抗耐药菌}

近年来，抗生素的不合理使用已经导致细菌产 生耐药性并不断增强, 这对人类健康构成巨大威 胁。金黄色葡萄球菌(Staphylococcus aureus, S. aureus)、 大肠杆菌 (Escherichia coli, E. coli)、铜绿假单胞菌 (Pseudomonas aeruginosa, P. aeruginosa) 等细菌也随 之产生多重耐药性。随着细菌耐药性的形成越来越 快、耐药谱越来越广、耐药强度越来越高, 迫使人 们必须寻找新的对抗耐药菌的方法。

\subsection{1 广谱抗菌}

许多由细菌造成的感染问题往往由多种细菌导 致，因此开发具有广谱抗菌性的纳米酶十分重要。 广谱抗菌，即对多种细菌均具有抑制或杀灭作用。 Wang 等 ${ }^{[42]}$ 发现超细金纳米颗粒(UsAuNPs)通过原 位还原生长在超薄二维金属有机框架(2D MOF)上, 所形成的纳米酶(UsAuNPs/MOF) 兼具 UsAuNPs 和 超薄 2D MOF 的优点, 并表现出显著的类过氧化物 酶活性。在较低浓度的 $\mathrm{H}_{2} \mathrm{O}_{2}$ 辅助下, UsAuNPs/MOF
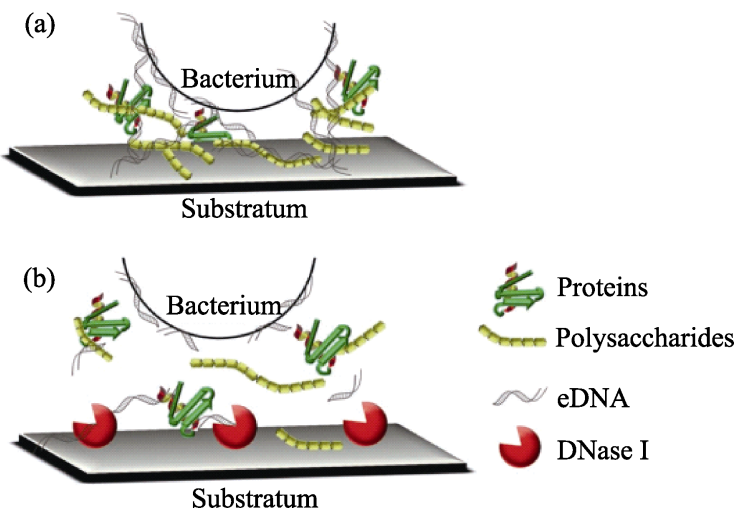

图 3 (a)eDNA 作为桥梁及(b)由 DNase 破坏 EPS 中 eDNA 成分 ${ }^{[41]}$

Fig. 3 (a) eDNA acting as a bridge, and (b) disruption of EPS by DNase attacking the eDNA component of the EPS ${ }^{[41]}$ 
纳米酶对革兰氏阴性菌大肠杆菌和革兰氏阳性菌金 黄色葡萄球菌均表现出优异的抗菌性能。动物实验 表明, 这种纳米酶能够有效促进伤口愈合, 并具有 良好的生物相容性。Gao 等 ${ }^{[43]}$ 设计了两种铜/碳纳米 酶(CuO-HCSs 和 $\mathrm{Cu}-\mathrm{HCSs}$ ), 其铜价态在 $\mathrm{Cu}^{0}$ 和 $\mathrm{Cu}^{2+}$ 可调节。这种纳米酶表现出铜价态依赖性的类过氧 化物酶、类过氧化氢酶和类超氧化物歧化酶活性。 对于 $\mathrm{CuO}$ 修饰的铜/碳纳米酶, 释放的 $\mathrm{Cu}^{2+}$ 可引起 革兰氏阴性菌大肠杆菌、菌鼠伤寒沙门氏菌 (Salmonella typhimurium, S. typhimurium) 和铜绿假 单胞菌的细胞膜损伤、脂质过氧化和 DNA 降解。 而对于 $\mathrm{Cu}$ 修饰的铜/碳纳米酶, 则通过类过氧化物 酶活性产生 ROS, 对革兰氏阴性细菌和革兰氏阳性 细菌起杀伤作用。

随着纳米酶研究的不断深入, 同时具有多重类 酶活性的纳米酶被逐渐开发出来并应用于抗菌。Qu 等 ${ }^{[44]}$ 发现将纳米金(AuNPs) 固定在生物功能化的双 功能介孔二氧化硅 $(\mathrm{MSN})$ 上, 所形成的纳米金体系 (MSN-AuNPs)(图 4(a,b)) 同时具有类过氧化物酶和 类氧化酶活性, 可将其应用于抗菌 (图 4(c, d))。 MSN-AuNPs 对于 $\mathrm{pH}$ 和温度变化均表现出较为稳定 的类酶活性, 这对于在恶劣环境下的抗菌应用十分 有用。进一步研究表明, MSN-AuNPs 催化产生的主 要活性中间体是 $\cdot \mathrm{OH} 、{ }^{1} \mathrm{O}_{2}$ 和 $\mathrm{O}_{2}{ }^{-}$。这些活性中间体 对大肠杆菌和金黄色葡萄球菌均具有显著的抗菌效
果(图 4(e,f))。此外, MSN-AuNPs 在分散已有的生物 膜和预防新的生物膜形成方面也显示出很高的效 率。Wang 等 ${ }^{[45]}$ 发现 $\mathrm{Cu}_{2} \mathrm{WS}_{4}$ 纳米晶体 (CWS NCS) 同样具有类氧化酶和类过氧化物酶的双重酶活性。 对金黄色葡萄球菌和大肠杆菌的灭活效率远优于大 多数报道的抗菌纳米材料, 甚至比广泛使用的抗生 素的效果都好。

单原子催化剂作为均相催化剂已广泛应用于化 学催化领域, 但在酶催化中的应用鲜有报道。最近, Yan 等 ${ }^{[46]}$ 将锌基咪唑骨架 ZIF-8(图 5(a))通过煅烧得 到含有以锌为中心的卟啉结构的碳纳米球 $\mathrm{PMCS}$ (图 5(b))。该纳米酶具有类似的过氧化物酶活 性，对铜绿假单胞菌的抑制率高达 99.87\%(图 5(e))。 在体内伤口感染实验中, PMCS 能够显著促进伤口 愈合, 且对生理组织无明显毒性。实验结果显示 PMCS 的酶活性源于配位不饱和的 $\mathrm{Zn}-\mathrm{N}_{4}$ 位点, 该 活性位点导致 $\mathrm{H}_{2} \mathrm{O}_{2}$ 的分解和・ $\mathrm{OH}$ 的形成(图 5(f))。 Dong 等 ${ }^{[47]}$ 通过模拟酶活性中心的空间结构合成了 具有高活性的单原子酶 $\mathrm{FeN}_{5} \mathrm{SA} / \mathrm{CNS}$ 。与常规的纳 米酶相比, 最大化的原子利用率和明确的活性位点 显著提高了这种纳米酶的类氧化酶活性。实验结果 显示, $\mathrm{FeN}_{5} \mathrm{SA} / \mathrm{CNS}$ 的催化效率是商用 $\mathrm{Pt} / \mathrm{C}$ 的 70 倍。同时, $\mathrm{FeN}_{5} \mathrm{SA} / \mathrm{CNS}$ 在体外具有广谱杀菌特性, 在体内具有伤口杀菌作用。基于上述报道, 单原子 纳米酶具有成为下一代纳米酶的巨大潜力。
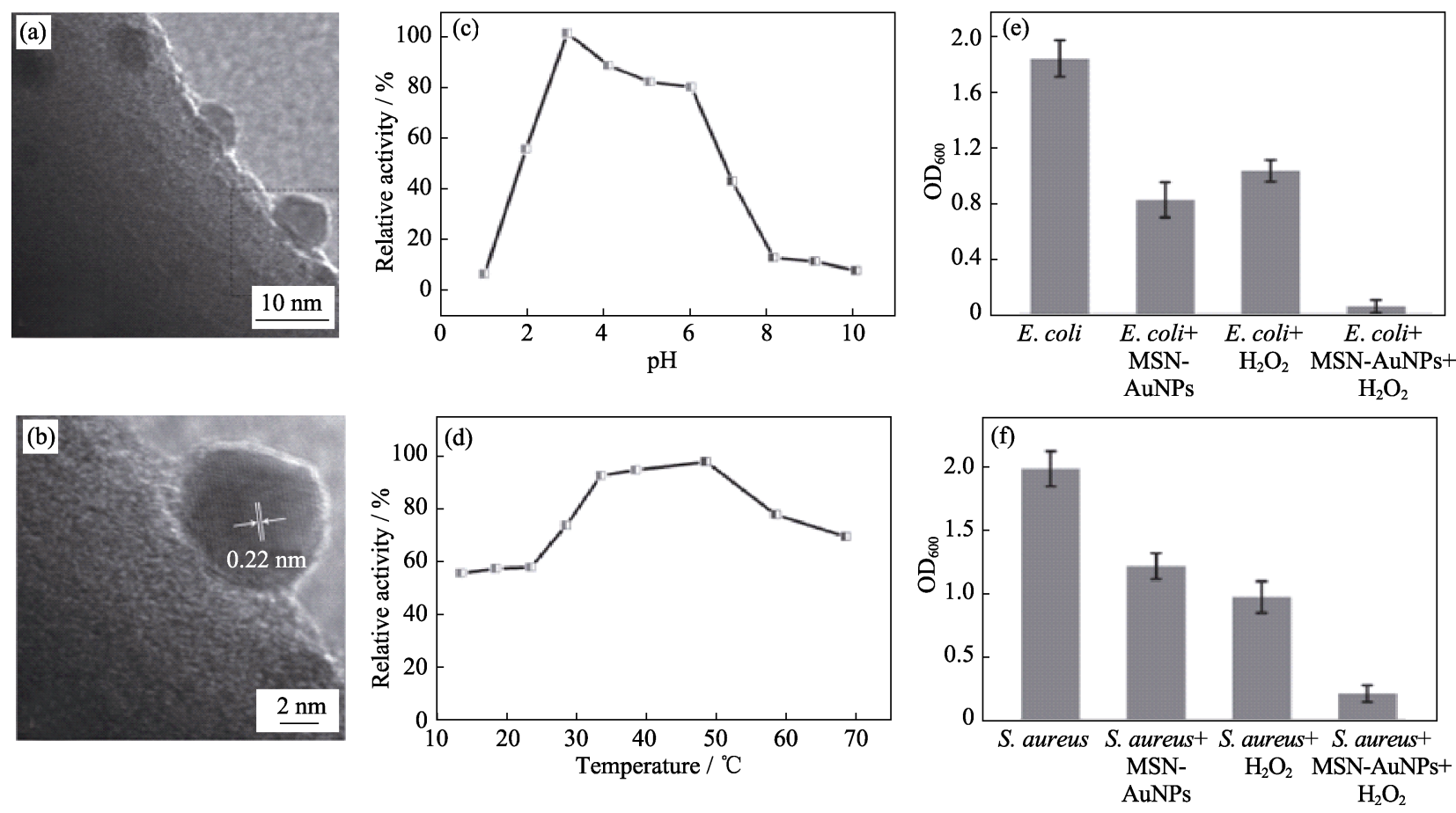

图 4 (a, b)MSN-AuNPs 在不同放大倍数下的 TEM 照片; 不同 $(\mathrm{c}) \mathrm{pH}$ 和(d)温度条件下 MSN-AuNPs 的酶活性; 不同条件处理的(e)大肠杆菌和(f)金黄色葡萄球菌的生长密度 ${ }^{[43]}$

Fig. 4 (a,b)TEM images of the MSN-AuNPs under different magnifications, enzyme activity of MSN-AuNPs under different (c) $\mathrm{pH}$ and (d) temperature conditions, and growth densities of (e) E. coli and (f) S. aureus under different conditions ${ }^{[43]}$ 


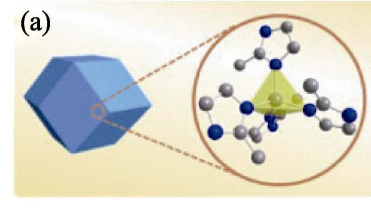

(b)
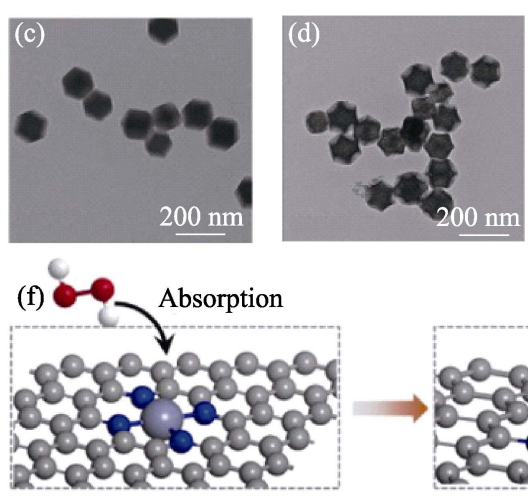

i. $\operatorname{PMCS}(*)$
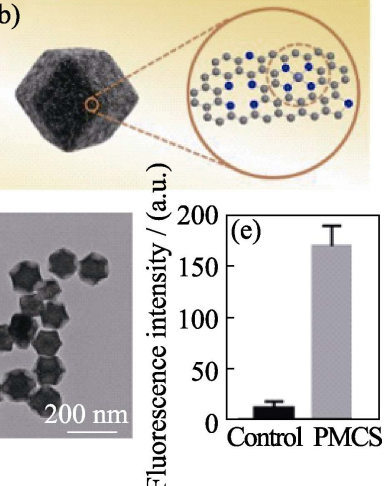

6

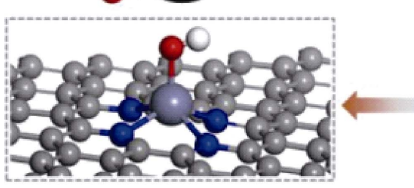

iv. $\mathrm{OH}^{*}+\cdot \mathrm{OH}$

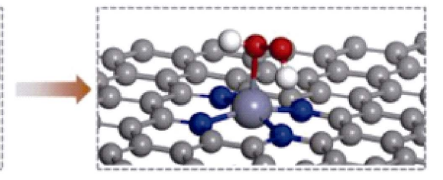

ii. $\mathrm{H}_{2} \mathrm{O}_{2}$

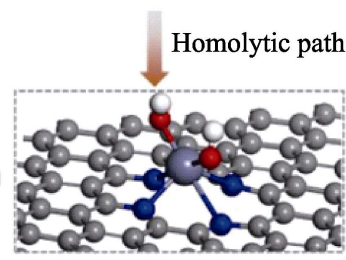

iii. $2 \mathrm{OH}^{*}$

图 5 (a)ZIF-8 结构框架和(b)碳纳米球 PMCS 结构模型, (c)ZIF-8 和(d)PMCS 的 TEM 照片, (e)对照和 PMCS 处理的 铜绿假单胞菌存活分析和(f)拟定的 PMCS 催化机理图 ${ }^{[46]}$

Fig. 5 (a) ZIF-8 structural framework and (b) PMCS structural model, TEM images of (c) ZIF-8 and (d) PMCS, (e) apoptosis analysis of $P$. aeruginosa treated with PMCS, and (f) proposed catalytic mechanism of $\mathrm{PMCS}^{[46]}$

\subsection{2 选择性抗菌}

近来，有研究发现纳米酶除了可以广谱杀死革 兰氏阴性菌和革兰氏阳性菌以外，还可以对细菌进 行选择性杀灭。选择性抗菌，即通过材料本身具有 的独特性质或者通过构筑赋予材料对细菌的化学响 应性，实现对细菌的选择性杀灭。Chen 等 ${ }^{[48]}$ 发现不 同晶面的钯 $(\mathrm{Pd})$ 纳米晶体对于革兰氏阴性菌和革兰 氏阳性菌具有抗菌选择性，具有晶面依赖性的类氧 化酶和类过氧化物酶活性。对于革兰氏阳性细菌金 黄色葡萄球菌, Pd 立方体显示出比 $\mathrm{Pd}$ 八面体更高的 抗菌活性。而对于革兰氏阴性细菌大肠杆菌, Pd 纳 米晶体的抗菌活性则相反。进一步研究显示, 这与 不同 $\mathrm{Pd}$ 纳米晶体的膜穿透能力有关。

除材料本身具有的抗菌选择性之外, $\mathrm{Qu}$ 等 ${ }^{[49]}$ 基 于二硫化钼 $\left(\mathrm{MoS}_{2}\right)$ 和光酸分子设计了一种智能革兰 氏选择性抗菌体系(Cit-MoS 2 )(图 6(a)), 赋予纳米酶 对细菌选择性杀灭的能力。如图 6(b)选择性抗菌, 一方面，根据不同菌株细胞壁组成和结构，通过调 节光照时间实现对 $\mathrm{MoS}_{2}$ 表面正负电荷比例的调控, 进而实现对不同细菌的选择性识别。另一方面, 光 酸分子对 $\mathrm{pH}$ 的降低, 活化了 $\mathrm{MoS}_{2}$ 的类过氧化物酶 活性, 增强了抗菌能力(图 6(c))。图 6(d)抗菌实验结 果显示, 在短时间 $(10 \mathrm{~min})$ 的照射下, Cit- $\mathrm{MoS}_{2}$ 对革 兰氏阳性细菌金黄色葡萄球菌就具有很强的杀灭能 力; 而对于革兰氏阴性菌细菌大肠杆菌，只需将照 射时间延长至 $25 \mathrm{~min}$ 即可达到抗菌效果。 (a)
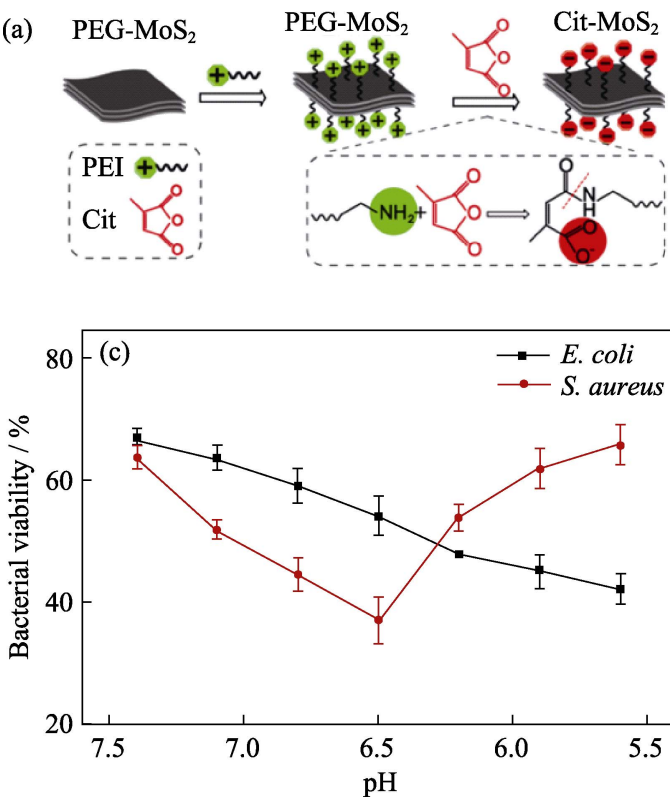

(b)
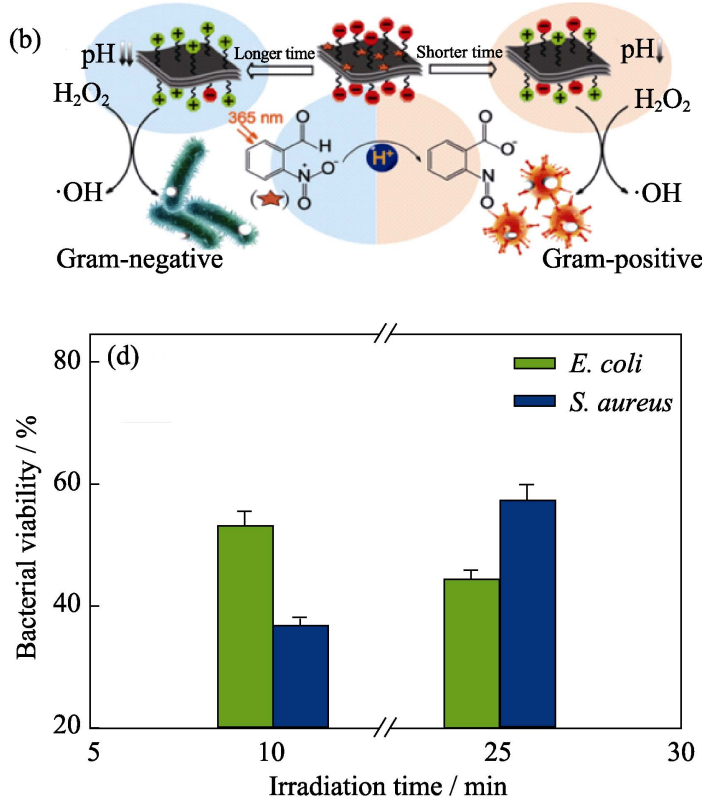

图 6 (a)Cit- $\mathrm{MoS}_{2}$ 的合成路线; (b)光调节 $\mathrm{Cit}-\mathrm{MoS}_{2}$ 酶活性以实现革兰氏选择性抗菌性能; 不同(c) $\mathrm{pH}$ 和(d)光照时间下细菌的存活率 ${ }^{[49]}$

Fig. 6 (a) Synthesis route of Cit- $\mathrm{MoS}_{2}$, and (b) illustration of light regulating Cit-MoS 2 enzyme activity to achieve Gram-selective antibacterial potential, and bacterial viabilities under different (c) $\mathrm{pH}$ and (d) irradiation time ${ }^{[49]}$ 


\subsection{3 协同抗菌}

单独使用某一抗菌模式很难实现对耐药细菌的 长期有效的对抗 ${ }^{[50]}$, 将多种抗菌模式联合使用是提 高抗菌效率行之有效的方法。因此, 将多种抗菌模 式整合至某一特定体系, 为制备具有高抗菌效率的 抗菌剂提供了新思路。

Zhao 等 ${ }^{[51]}$ 发现聚乙二醇修饰的二硫化钼 $\left(\mathrm{PEG}-\mathrm{MoS}_{2}\right)$ 纳米花通过类过氧化物酶活性和光热 效应的协同作用，实现了对大肠杆菌和枯草芽狍杆 菌(Bacillus subtilis)的快速有效杀灭, 并且具有促进 伤口愈合的作用。协同杀菌过程中, PEG-MoS 2 纳米 花首先分解 $\mathrm{H}_{2} \mathrm{O}_{2}$ 产生・ $\mathrm{OH}$, 破坏细胞膜, 使细胞脆 弱易受攻击。其具有的光热性质进一步对细菌造成 杀伤作用，协同杀菌效率高达 $80 \%$ 。

$\mathrm{Qu}$ 等 ${ }^{[52]}$ 将透明质酸 $(\mathrm{HA})$ 官能化的石墨烯一介孔 二氧化硅(HA-GS)纳米片作为载体, 随后在表面修 饰透明质酸-多巴胺复合物(HA-DA)。万古霉素改性
的 $\mathrm{Fe}_{3} \mathrm{O}_{4} \mathrm{MNPs}$ 通过与多巴胺的强相互作用结合在 纳米片上, 构建成智能抗菌体系(图 7(a))。由于万古 霉素的靶向作用, HA 被细菌分泌的透明质酸酶 (Hyal) 降解后, 释放抗坏血酸(AA)。AA 可以被 $\mathrm{Fe}_{3} \mathrm{O}_{4}$ MNPs 催化产生强氧化性的・OH(图 7(b))。这 种智能抗菌体系对金黄色葡萄球菌和大肠杆菌均具 有很强的杀灭作用(图 7(c,d))。此外，由于石墨烯的 光热特性进一步实现了协同抗菌效果, 仅 2.6 和 $1.7 \mathrm{mg} \cdot \mathrm{mL}^{-1} \mathrm{AA}$ 就可以将两种细菌的存活率抑制在 $10 \%$ 以下。

通常认为, 纳米材料可以通过物理或化学方式 杀灭细菌。在物理上, 诸如石墨烯及其衍生物之类 的纳米材料可以通过机械叶片效应，包裹细胞膜或 破坏性地从细胞膜中提取磷脂来灭活细菌 ${ }^{[53]}$ 。另一 方面，金属氧化物纳米材料可以通过释放有毒金属 离子或产生 ROS 等化学途径杀死细菌 ${ }^{[54]}$ 。但是, 这 些纳米材料在处理具有多重耐药性的细菌时会降低

(a)

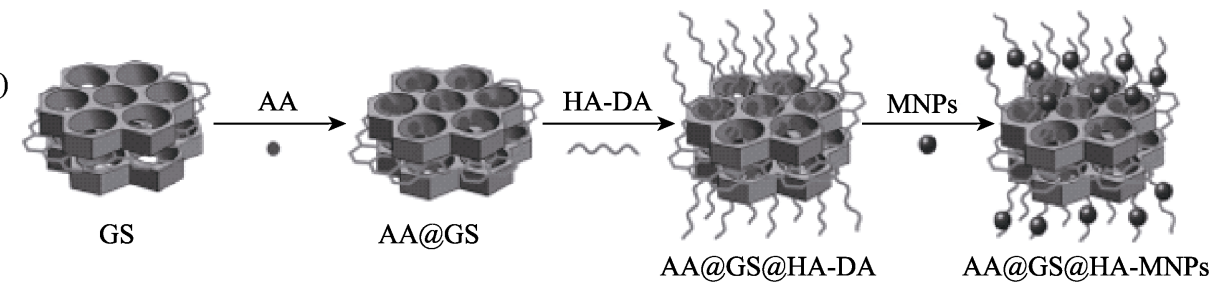

(b)
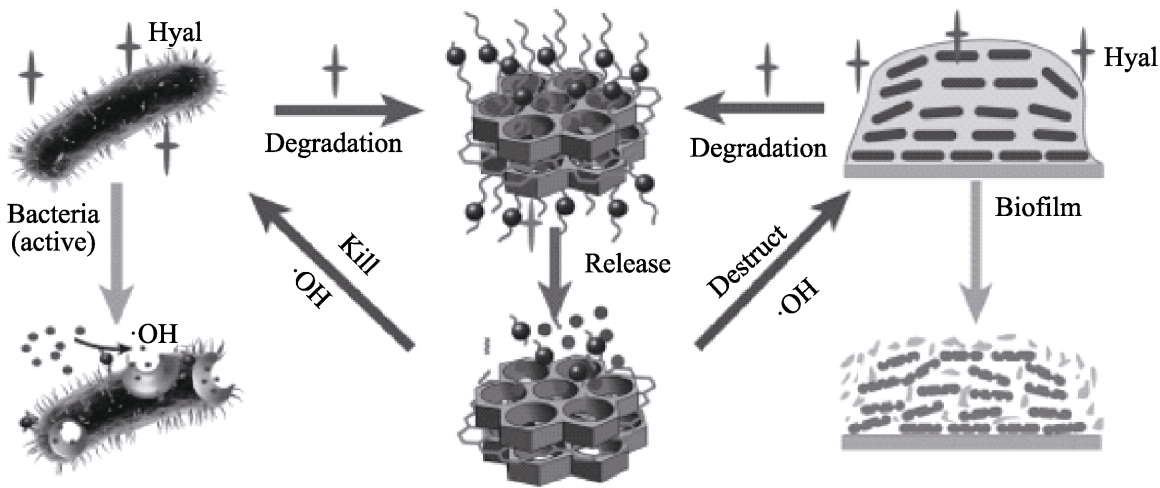

Bacteria (inactive)

Biofilm disperse \& bacteria killing
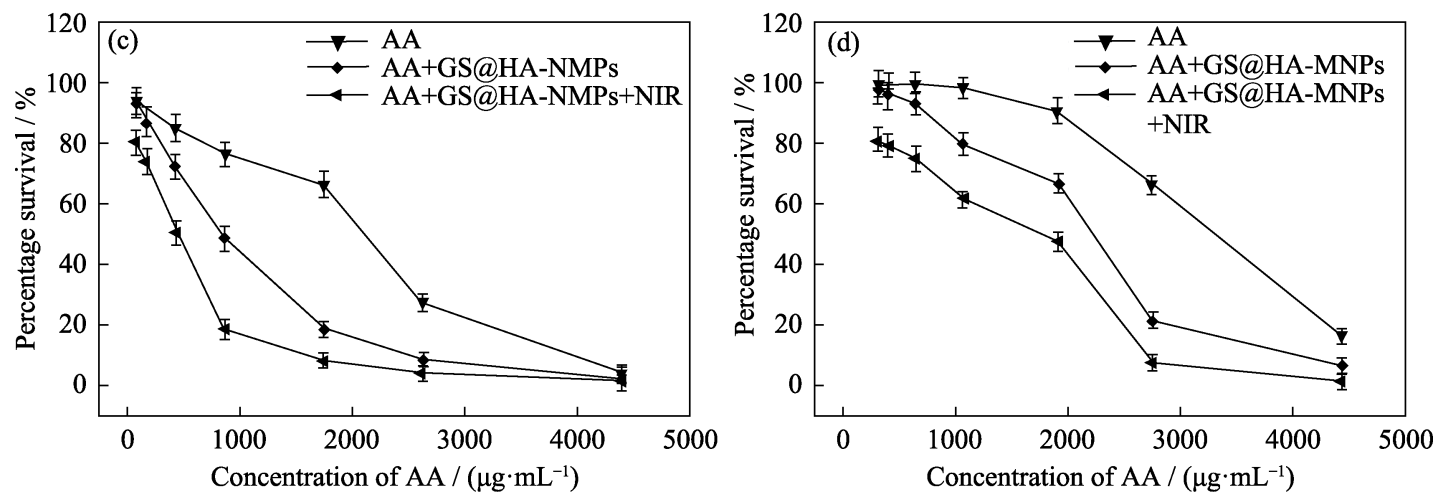

图 7 (a)抗菌平台的制备及其(b)抗菌示意图，不同浓度抗坏血酸处理的(c)金黄色葡萄球菌和(d)大肠杆菌的存活率 ${ }^{[52]}$

Fig. 7 (a) Preparation of the antibacterial platform, and its (b) schematic diagram of antibacterial, and survival rates of (c) S. aureus and (d) E. coli treated with different concentrations of ascorbic acid ${ }^{[52]}$ 
其功效 ${ }^{[55]}$ 。为了克服这个问题, $\mathrm{Lu}$ 等 ${ }^{[56]}$ 设计合成的 集成硫化铜纳米颗粒 $(\mathrm{CuS} \mathrm{NPs})$ 与氧化石墨烯纳米 片(GO NSs), 是具有物理和化学双重抗菌作用的纳 米复合材料 $(\mathrm{CuS} / \mathrm{GO} \mathrm{NC})$ 。一方面, $\mathrm{CuS} / \mathrm{GO} \mathrm{NC}$ 具 有独特的针状形态，可物理损伤细菌细胞膜; 另一 方面, $\mathrm{CuS} / \mathrm{GO} \mathrm{NC}$ 通过类氧化酶和类过氧化物酶活 性化学杀死细菌, 只需一次给药即可杀死多重耐药 性细菌(如耐甲氧西林的金黄色葡萄球菌(MRSA))。 此外, $\mathrm{CuS} / \mathrm{GO} \mathrm{NC}$ 还具有促进伤口愈合的作用。这 项研究提供了一种新的抗菌策略, 可以结合纳米材 料的物理和化学抗菌模式, 以开发更有效的疗法来 对抗多重耐药性细菌。

目前利用纳米酶对抗的耐药性细菌主要为大肠 杆菌和金黄色葡萄球菌, 对于其他耐药性细菌的抗 菌效果还需进一步验证。

\section{2 消除生物膜}

细菌耐药性的产生与细菌生物膜有着不可分割 的关系 ${ }^{[57]}$ 。由于细菌生物膜的存在, 抗菌剂很难杀 灭被胞外基质包裹在生物膜内的细菌 ${ }^{[8]}$, 由此造成 生物膜内的细菌对抗菌剂的敏感性降低, 从而形成 强大的耐药性并诱导产生新的生物膜 ${ }^{[59]}$ 。研究发现, 细菌形成生物膜后会降低细菌对药物的敏感性, 当
细菌脱离生物膜形成游离细菌后对药物敏感性又重 新得到恢复。即使是没有耐药性遗传的细菌, 当形 成生物膜后, 其对抗菌剂的敏感性也会大大降低 ${ }^{[60]}$ 。此 外, 许多由细菌感染导致的相关疾病均有细菌生物 膜的参与 ${ }^{[3]}$ 。因此, 消除细菌生物膜不仅可使抗菌剂 进入细菌内部，根除耐药菌，同时也可预防细菌感 染，减少相关疾病的发生。

Gao 等 ${ }^{[61]}$ 发现具有类过氧化物酶活性的 $\mathrm{Fe}_{3} \mathrm{O}_{4}$ MNPs 在酸性条件下可以催化 $\mathrm{H}_{2} \mathrm{O}_{2}$ 降解 DNA、蛋 白质和多糖等细菌生物膜成分。对铜绿假单胞菌的 杀灭效果比单独使用 $\mathrm{H}_{2} \mathrm{O}_{2}$ 提高了 10 倍以上。随后, $\mathrm{Gao}$ 等 ${ }^{[62]}$ 通过含 $\mathrm{Fe}_{3} \mathrm{O}_{4} \mathrm{MNPs}$ 的纳米酶 CAT-NP, 可 同时降解生物膜 EPS 基质并快速杀灭细菌，具有抗 龊齿的功能。最近, Gao 等 ${ }^{[63]}$ 进一步报道了葡萄糖包 被氧化铁纳米颗粒制备而成的纳米酶用于抗嚙齿。 葡萄糖涂层促进了纳米酶与细菌细胞的特异性结合, 同时有利于纳米酶渗入并通过其类过氧化物酶活性 降解生物膜 EPS 基质。该种纳米酶显著降低了龉齿 病变的发生和严重程度。

$\mathrm{Qu}$ 等 ${ }^{[64]}$ 设计构建了一种基于多核金属配合物 的 DNase(DMAE)(图 8(a))。将钝化的含 $\mathrm{Ce}(\mathrm{IV})$ 的 $\mathrm{Au} \mathrm{NPs}$ 组装到 $\mathrm{Fe}_{3} \mathrm{O}_{4} / \mathrm{SiO}_{2}$ 核壳胶体颗粒表面, 其微
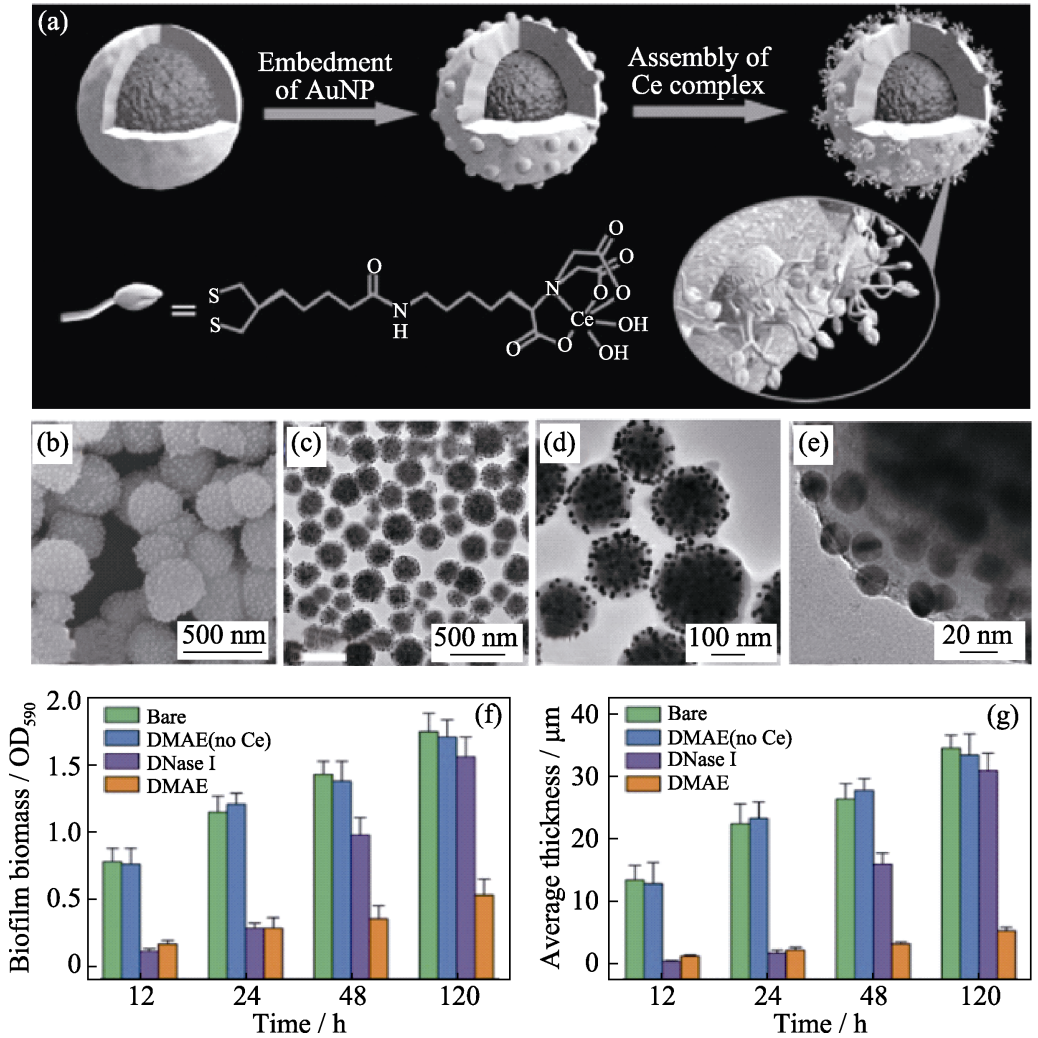

图 8 (a)DMAE 的制备; 组装在核/壳颗粒表面的金纳米颗粒的(b)SEM、(c)TEM 和(d, e)放大 的 TEM 照片; (f)生物膜生长情况和 $(\mathrm{g})$ 形成生物膜的平均厚度 ${ }^{[64]}$

Fig. 8 (a) Preparation of DMAE and its (b) TEM and (c) SEM images, as well as magnified (d, e) TEM images of Au NPs confined on the surface of core/shell particles, and (f) growth of biofilms and (g) average thickness of the biofilms ${ }^{[64]}$ 
观形貌如图 8(b e) 所示。当 DMAE 涂在基质表面上时, 通过降解 EPS 中存在的 eDNA, 不仅可在 $120 \mathrm{~h}$ 内大 大减少细菌粘附, 并可防止生物膜的形成(图 8(f,g)), 还可降解成熟生物膜中的 eDNA, 破坏生物膜结构 的完整性，有利于抗生素进入生物膜内部。

$\mathrm{Qu}$ 等 ${ }^{[65]}$ 在前述工作的基础上又设计了一种具 有类 DNase 和类过氧化物酶双重酶活性的基于 $\mathrm{MOF} / \mathrm{Ce}$ 结构的纳米酶。一方面, 嫁接到 $\mathrm{MOF}$ 的 $\mathrm{Ce}$ 配合物可使纳米酶表现出优异的类 DNase 酶活 性, 高效地催化 eDNA 降解。另一方面, 掺有 $\mathrm{Au}$ 的 MOF 显示出增强的类过氧化物酶活性。由于 Ce(IV) 配合物能够降解 eDNA 并破坏已建立的生物膜, 因 而其具有类过氧化物酶活性的 $\mathrm{MOF}$ 在 $\mathrm{H}_{2} \mathrm{O}_{2}$ 存在下 可以杀死分散在生物膜中的细菌。此外, 这种纳米 酶还能促进伤口愈合和减少炎症的发生。

由于正常组织细胞同样具有生物膜组分, 对于 将这种具有解离生物膜结构、解除生物膜功能的纳 米酶应用于生物体, 是否会对生物体造成损伤, 急 需通过体内实验给予明确回答, 不可忽视这类功能 纳米酶的生物安全性。

\section{3 海洋防污}

海洋生物污损是指海洋生物附着生长在海洋人 工设施表面, 对人工设施的正常运转造成严重影响 的现象。海洋生物污损的形成通常有以下几个步 骤 ${ }^{[66]}$ : 1)海洋微生物调节膜的形成: 由蛋白质、多 糖、糖蛋白等可溶性有机碳通过物理吸附方式在基 质表面累积形成调节膜; 2)微生物膜的形成: 细菌 等原核微生物通过物理作用附着在基膜上, 形成微 生物膜; 3)小型污损生物的附着: 以微生物为食的 小型多细胞生物在生物膜上附着成膜; 4)大型污损 生物包括藤壶、苔藓虫的生长。其造成的损害包括 增加船舶航行阻力而降低航速、堵塞管道、腐蚀金 属、造成生物入侵等，由此每年产生的资源浪费不 计其数 ${ }^{[67]}$ 。

海洋防污是以在船舶等人工设施表面涂覆防污 涂料为主要方法。将纳米材料引入防污涂料已是较 为常用的方法。纳米材料在防污涂料中的使用主要 有三种形式 ${ }^{[68]}$ : 1) 利用纳米材料自身的强抗菌性能 作为防污剂引入涂料中, 增强防污涂料的防污能力; 2)通过纳米颗粒制备具有微米或纳米阶层的防污涂 料表面, 增大涂层接触角, 抑制污损生物的附着; 3) 将 纳米材料作为防污剂的载体, 缓慢释放防污剂, 提 高防污剂的使用效率。

海水中含有约 $1 \mathrm{mmol} / \mathrm{L}$ 的 $\mathrm{Br}^{-}$和 $500 \mathrm{mmol} / \mathrm{L}$ 的 $\mathrm{Cl}^{-}$, 可提供卤化反应充足的卤素离子。Tremel 等 ${ }^{[69]}$ 发现五氧化二钒纳米线 $\left(\mathrm{V}_{2} \mathrm{O}_{5}\right.$ nanowires) 具有
类卤代过氧化物酶活性，在海水条件下可产生 $\mathrm{HOBr}$ 和 ${ }^{1} \mathrm{O}_{2}$ 。将 $\mathrm{V}_{2} \mathrm{O}_{5}$ 纳米线混合在市售涂料中涂覆于不 锈钢表面, 在海水中可显著抑制微生物粘附, 有效 防止生物膜的形成, 具有很强的防污性能。基于 $\mathrm{V}_{2} \mathrm{O}_{5}$ 的晶体结构 ${ }^{[70]}$ 和动力学参数提出的溴化反应 机制为: $\mathrm{V}_{2} \mathrm{O}_{5}$ 纳米线的裸露晶面具有类似于钒卤代 过氧化物酶活性位点的钒配位几何结构, 由于添加 了 $\mathrm{H}_{2} \mathrm{O}_{2}$, 在 $\mathrm{Br}^{-}$的亲核进攻下, 在纳米线表面形成 一种过氧中间体，随后形成 $\mathrm{HOBr}$ 。

尽管 $\mathrm{V}_{2} \mathrm{O}_{5}$ 显示出较高的类卤代过氧化物酶活 性, 但由于其毒性和可能的致突变、致癌、致畸性 ${ }^{[71]}$, 其大规模应用受到很大限制。受氧化铈在卤化反应 中的催化活性、氧化卤化作用, 以及 $\mathrm{Ce}^{3+} / \mathrm{Ce}^{4+}$ 氧化 还原电对的启发, Tremel 等 ${ }^{[72]}$ 进一步发现氧化铈纳 米棒 $\left(\mathrm{CeO}_{2-x} \mathrm{NRs}\right)$ (图 9(a, b)) 也具有类卤代过氧化物 酶活性。将 $\mathrm{CeO}_{2-x} \mathrm{NRs}$ 掺杂在市售涂料后的海水挂 板实验，发现涂有掺杂 $\mathrm{CeO}_{2-x} \mathrm{NRs}$ 涂料的挂板受污 染程度明显较低(图 9(c))。后续的研究发现 $\mathrm{CeO}_{2-x}$ $\mathrm{NRs}$ 的催化机制不同于 $\mathrm{V}_{2} \mathrm{O}_{5}$ 纳米线, $\mathrm{CeO}_{2-x} \mathrm{NRs}$ 以 产生自由基为催化机制。 $\mathrm{H}_{2} \mathrm{O}_{2}$ 与 $\mathrm{CeO}_{2-x}\{110\}$ 面的 $\mathrm{Ce}(\mathrm{III})$ 原子配位后, $\mathrm{Ce}(\mathrm{III})$ 氧化成 $\mathrm{Ce}(\mathrm{IV})$ 并伴随 $\mathrm{O}-\mathrm{O}$ 键断裂形成 $\mathrm{OH}^{-}$和・ $\mathrm{OH}($ 图 9(d))。随后 $\cdot \mathrm{OH}$ 与 $\mathrm{Br}^{-}$结合, 重组生成 $\mathrm{HOBr}$ 。

基于上述工作, Tremel 等 ${ }^{[73]}$ 后续通过静电纺丝 (Electrospinning)技术将 $\mathrm{CeO}_{2-x}$ 纳米棒嵌入聚乙烯醇 (PVA)纤维中制成纳米纤维垫(图 $10(\mathrm{a} \sim \mathrm{c}))$ 。聚合物 纤维提供多孔结构, 使亲水性小分子 $\left(\mathrm{H}_{2} \mathrm{O}_{2}\right.$ 和 $\left.\mathrm{Br}^{-}\right)$ 易进入内嵌的 $\mathrm{CeO}_{2-x}$ 纳米棒, 触发催化反应。 $22 \mathrm{wt} \% \mathrm{CeO}_{2-x}$ 纳米棒嵌入的 PVA 垫可使细菌粘附 降低 69\%, 远优于纯 PVA 垫(图 10(d))。

尽管这类纳米酶应用于海洋防污有其过人之处, 但是仍需解决以下问题: 1)海洋中虽然有着丰富的 卤素离子, 但是 $\mathrm{H}_{2} \mathrm{O}_{2}$ 含量仅有 100 250 nmol/L, 与 文献报道相差甚远。(2)这类纳米酶需借助载体形成 防污涂料, 其与载体的相容性和最终导致的催化效 率有待商榷。本课题组正着力于此方面的研究, 尝 试将这类纳米酶与其他体系联合 (例如光催化), 在 海洋仪器服役过程中, 通过太阳光辐射将海水转化 为 $\mathrm{H}_{2} \mathrm{O}_{2}$, 不但弥补海洋中 $\mathrm{H}_{2} \mathrm{O}_{2}$ 不足的问题, 而且 使产生的 $\mathrm{H}_{2} \mathrm{O}_{2}$ 能够与纳米酶催化产生的 HOX 起到 协同杀菌的作用。

\section{6 总结与展望}

综上所述, 纳米酶在抗菌应用方面已经取得了 显著成果。纳米酶通过自身具有的类天然酶活性, 


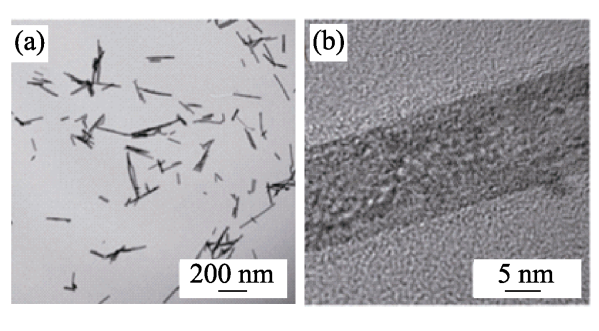

(c)
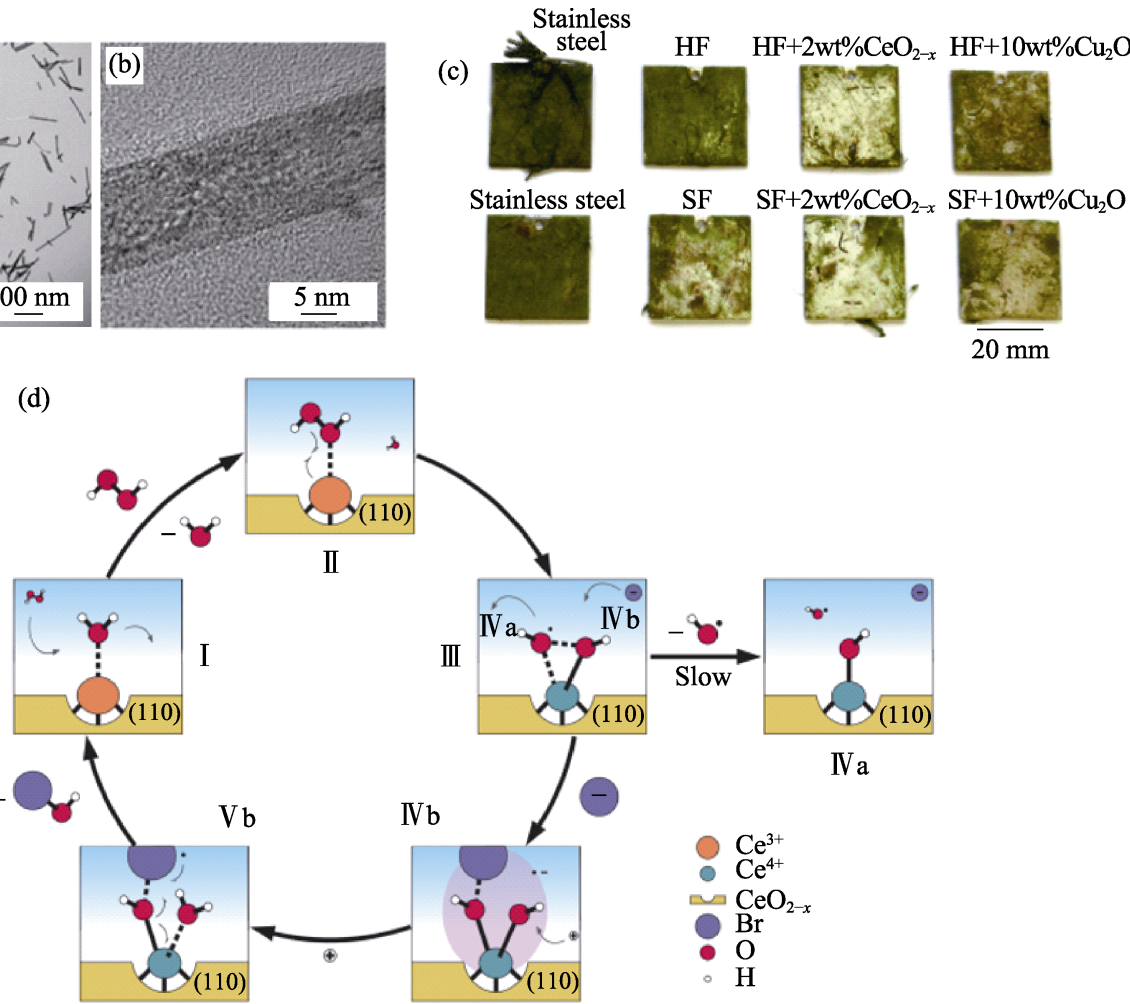

图 $9 \mathrm{CeO}_{2-x}$ 纳米棒的(a)TEM 和(b)HRTEM 照片, (c)海洋挂板实验, (d)拟定的 $\mathrm{CeO}_{2-x}$ 纳米棒催化溴化机理 ${ }^{[72]}$

Fig. 9 (a) TEM and (b) HRTEM images of $\mathrm{CeO}_{2-x} \mathrm{NPs}$, (c) ocean hanging board experiment, and (d) proposed catalytic bromination mechanism of the $\mathrm{CeO}_{2-x} \mathrm{NPs}^{[72]}$
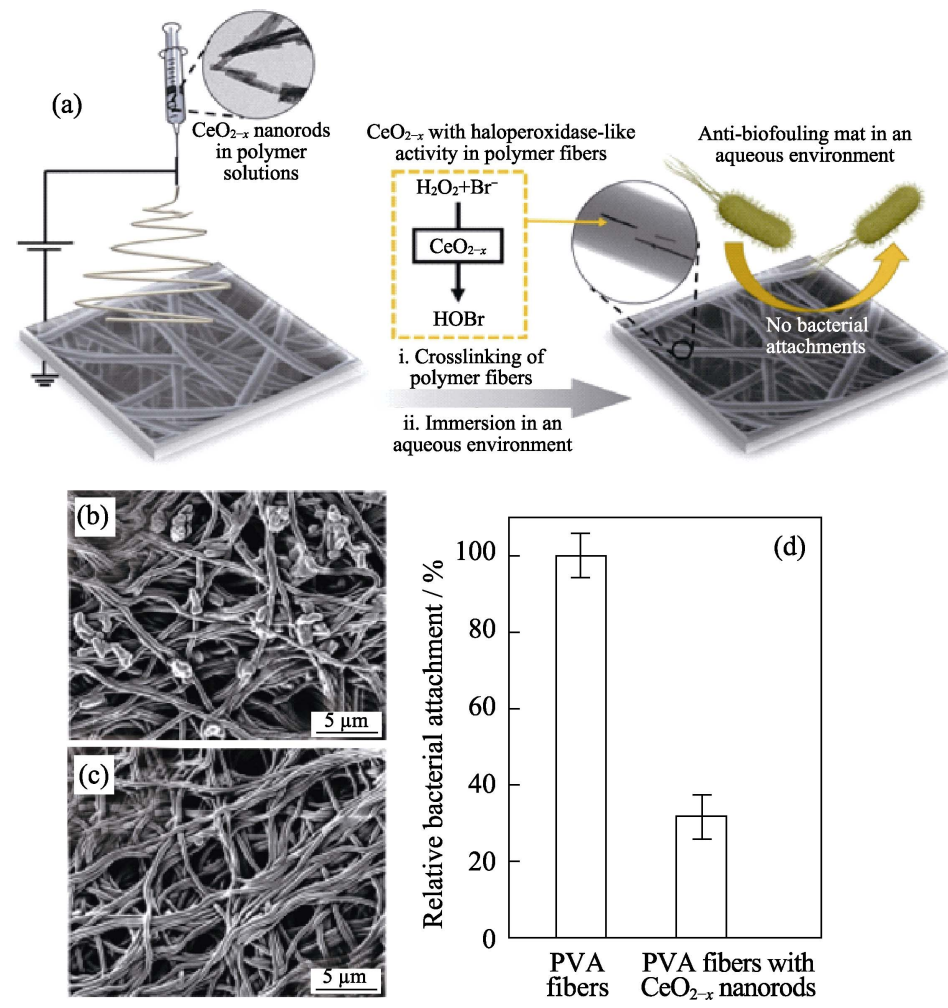

图 10 (a)纳米纤维垫的制备及防污示意图, (b)未填充和(c)填充 $\mathrm{CeO}_{2-x}$ 纳米棒的 PVA 垫抑菌 SEM 照片, (d)22wt\%填充 PVA 垫的细菌附着对比 ${ }^{[73]}$

Fig. 10 (a) Schematic diagram of preparation and anti-fouling of nanofibrous, SEM images of PVA (b) without and (c) with $\mathrm{CeO}_{2-x} \mathrm{NRs}$ after incubation, and (d) comparison of bacterial adhesion between $22 \mathrm{wt} \%$ filled and unfilled PVA nanofibrous ${ }^{[73]}$ 
分别以催化产生强氧化性活性氧自由基破坏细菌生 物膜成分、产生次卤酸干扰细菌生存重要的群体感 应系统和降解细菌生物膜中外源性 DNA 的途径, 而达到抗菌的目的。相比于天然酶和传统抗菌剂, 纳米酶具有稳定性好、成本低、易于功能化等优点。 根据相关报道 ${ }^{[8]}$, 由于纳米材料杀伤作用是多方面 的, 细菌很难形成针对性的抗药性。例如, 小分子修 饰的 AuNPs 具有优良的抗菌活性, 而且与现有抗生 素相比很难诱导细菌产生耐药性 ${ }^{[74]}$ 。因此纳米酶作 为新兴纳米材料, 人们对其对抗耐药性细菌并且避 免耐药性产生方面, 有足够的信心。

但这一领域，仍有许多问题和挑战有待突破：1) 纳米酶体系的完善。除了报道的大量关于类过氧化 物酶活性的纳米酶外, 其他纳米酶体系还有待完善 与开发。2)纳米酶抗菌谱未知。目前纳米酶抗菌主 要针对金黄色葡萄球菌、大肠杆菌、芽狍杆菌等。 对于其他细菌的杀菌效果究竟如何, 还需要进一步 探索明确。3)纳米酶抗菌特异性有待探索。纳米酶 的抗菌体系往往具有广谱抗菌性, 实现纳米酶的特 异性和选择性抗菌需要突破。4)纳米酶的多重酶活 性有待揭示。许多纳米酶同时具有多种类酶性质, 其是否会相互干扰尚不清楚。5)纳米酶的催化效率 需要明确。纳米酶的催化效率远无法达到天然酶的 水平, 并且纳米酶存在底物选择性差的问题。6)纳 米酶的生物安全性有待证实。纳米酶的抗菌应用主 要集中在体外生物实验, 对于体内应用的研究还很 少。生物安全性问题应引起足够的重视。

纳米酶抗菌应用的研究处于起步阶段, 上述存 在的问题不容忽视。基于文献总结和分析，对于纳 米酶未来抗菌的研究, 本课题组提出了以下几个方 面供同行参考: 1)通过优化纳米酶尺寸或功能化修 饰提高抗菌效率。2)通过结合特异性识别细菌的小 分子, 实现纳米酶的特异性杀菌。3)通过与其他抗 菌体系联合, 起到协同杀菌作用, 从而进一步提高 抗菌效率。4)通过纳米酶自身催化性质, 对于主流 抗菌体系进行补充, 充分发挥主流抗菌体系的抗菌 效果。我们相信随着研究的不断深入, 纳米酶作为 新型抗菌剂会逐渐运用于人类的生产与生活之中。

\section{参考文献:}

[1] RIZZELLO L, POMPA P P. Nanosilver-based antibacterial drugs and devices: mechanisms, methodological drawbacks, and guidelines. Chemical Society Reviews, 2014, 43(5): 1501-1518.

[2] WANG LI-SHENG, GUPTA A, ROTELLO V M. Nanomaterials for the treatment of bacterial biofilms. ACS Infections Dieases, 2015, 2(1): 3-4.

[3] YANG LIANG, LIU YANG, WU HONG. Combating biofilms. Fems
Immunology \& Medical Microbiology, 2012, 65(2): 146-157.

[4] SIMOES MANUEL. Antimicrobial strategies effective against infectious bacterial biofilms. Current Medicinal Chemistry, 2011, 18(14): 2129-2145.

[5] GAO LI-ZENG, ZHUANG JIE, LENG NIE, et al. Intrinsic peroxidase-like activity of ferromagnetic nanoparticles. Nature Nanotechnology, 2007, 2(9): 577-583.

[6] YAN XI-YUN. Nanozyme: a new type of artificial enzyme. Progress in Biochemistry and Biophysics, 2018, 45(2): 101-104.

[7] WEI HUI, WANG ERKANG. Nanomaterials with enzyme-like characteristics (nanozymes): next-generation artificial enzymes. Chemical Society Reviews, 2013, 42(14): 6060-6093.

[8] TANG YAN, QIU ZHI YUE, XU ZHUO BING. Antibacterial mechanism and applications of nanozymes. Progress in Biochemistry and Biophysics, 2018, 45(2): 118-128.

[9] JIANG DA-WEI, NI DA-LONG, ROSENKRANS Z T. Nanozyme: new horizons for responsive biomedical applications. Chemical Society Reviews, 2019, 48(14): 3683-3704.

[10] LIANG MIN-MIN, YAN XI-YUN. Nanozyme: from new concepts, mechanisms, and standards to applications. Accounts of Chemical Research, 2019, 52(8): 2190-2200.

[11] LAURENTS D V, BALDWIN R L. Characterization of the unfolding pathway of hen egg with white lysozyme. Biochemistry, 1997, 36(6): 1496-1504.

[12] FATMA V, DE M W C M A, PINAR A, et al. Antimicrobial strategies centered around reactive oxygen species-bactericidal antibiotics, photodynamic therapy, and beyond. FEMS Microbiology Reviews, 2013, 37(6): 955-989.

[13] HOU YA-XIN, ZHANG RUO-FEI, YAN XI-YUN, et al. Nanozymes: a new choice for disease treatment. Science Sinica(Vitae), 2020, 50(3): $311-328$.

[14] NELSON D, ROSA M A, ALESSANDRO D, et al. Applications of laccases and tyrosinases (phenoloxidases) immobilized on different supports: a review. Enzyme \& Microbial Technology, 2002, 31(7): 907-931.

[15] ZUO PENG, YU SHAO-MING, YANG JIE-RU, et al. Research progress in support material for immobilization of horseradish peroxidase. Materials Review, 2007, 21(11): 46-49.

[16] VEITHC N C. Horseradish peroxidase: a modern view of a classic enzyme. Phytochemistry (Amsterdam), 2004, 65(3): 249-259.

[17] WU JIANG-JIEXING, WANG XIAO-YU, WANG QUAN, et al. Nanomaterials with enzyme-like characteristics (nanozymes): nextgeneration artificial enzymes (II). Chemical Society Reviews, 2019, 48(4): 1004-1076.

[18] JIANG BING, FANG LONG, WU KONG-MING, et al. Ferritins as natural and artificial nanozymes for theranostic. Theranostics, 2019, 10(2): 687-706.

[19] CHEN ZHAO-WEI, WANG ZHEN-ZHEN, REN JINSONG, et al. Enzyme mimicry for combating bacterial and biofilms. Accounts of Chemical Research, 2018, 51(3): 789-799.

[20] MURRAY P J, WYNN T A. Protective and pathogenic functions of macrophage subsets. Nature Reviews Immunology, 2011, 11(11): 723-737.

[21] LOO A E K, WANG Y T, HO R J, et al. Effects of hydrogen peroxide on wound healing in mice in relation to oxidative damage. PLOS One, 2012, 7(11): 49215.

[22] RAGG R, TAHIR M N, TREMEL W. Solids go bio: inorganic nanoparticles as enzyme mimics. European Journal of Inorganic Chemistry, 2016(13/14): 1906-1915.

[23] ASATI ATUL SANTRA, SANTIMUKUL KAITTANIS, CHARALAMBOS NATH, et al. Oxidase-like activity of polymercoated cerium oxide nanoparticles. Angewandte Chemie International Edition, 2009, 48(13): 2308-2312. 
[24] ASATI A, KAITTANIS C, SANTRA S, et al. pH-tunable oxidaselike activity of cerium oxide nanoparticles achieving sensitive fluorigenic detection of cancer biomarkers at neutral $\mathrm{pH}$. Analytical Chemistry, 2011, 83(7): 2547-2553.

[25] FATMA V, DE M W C M A, PINAR A, et al. Antimicrobial strategies centered around reactive oxygen species-bactericidal antibiotics, photodynamic therapy, and beyond. FEMS Microbiology Reviews, 2013, 6(6): 955-989.

[26] HOFLER G T, BUT A, HOLLMANN. Haloperoxidase as catalysts in organic synthesis. Orgainc \& Biomolecular Chemistry, 2019, 17(42): 9267-9274.

[27] SHAW P D, HAGER L P. Choroperoxidase: a component of the $\beta$-ketoadipate chlorinase system. Journal of Biological Chemistry, 1961, 236(6): 1626-1630.

[28] TIMMINS A, VISSER S P D. Enzymatic halogenases and haloperoxidases: computantional studies on mechanism and function. Advances in Protein Chemistry \& Structural Biology, 2015, 100: $113-151$.

[29] KAROLINE H, HAJO F, FELIX P, et al. Functional enzyme mimics for oxidative halogenation reactions that combat biofilm formation. Advanced Materials, 2018, 30(36): 1701703.

[30] THOMAS E L. Myeloperoxidase-hydrogen peroxide-chloride antimicrobial system: effect of exogenous amines on antibacterial action against Escherichia Coli. Infection \& Immunity, 1979, 25(1): $110-116$.

[31] REIS P A, MARTINS M L, ARAUJO E F, et al. AiiA quorumsensing quenching controls proteolytic activity and biofilm formation by enterobacter cloacae. Current Microbiology, 2012, 65(6): 758-763.

[32] ZHANG JING-JING, FENG TAO, WANG JIA-YI, et al. The mechanisms and applications of quorum sensing (QS) and quorum quenching (QQ). Journal of Ocean University of China, 2019, 18(6): $1427-1442$.

[33] BEZEK K, KURINI M, KNAUDER E, et al. Attenuation of adhesion, biofilm formation and quorum sensing of campylobacter jejuni by euodia ruticarpa. Phytotherapy, 2016, 30(9): 1527-1532.

[34] TAUNK A, CHEN R, ISKANDER G, et al. Dual-action biomaterial surfaces with quorum sensing inhibitor and nitric oxide to reduce bacterial colonization. ACS Biomaterials Science \& Engineering, 2018, 4(12): 4174-4182.

[35] CORDONNIER C, BERNARDI G. A comparative study of acid deoxyribonucleases extracted from different tissues and species. Canadian Journal of Biochemistry, 1968, 46(8): 989-995.

[36] MEHTA H J, BISWAS A, PENLEY A M, et al. Management of intrapleural sepsis with once daily use of tissue plasminogen activator and deoxyribonuclease. Respiration, 2016, 91(2): 101-106.

[37] GRUBER B, KATAEV E, ASCHENBRENNER J, et al. Vesicles and micelles from amphilic zinc( II )-cyclen complexes as highly potent promoters of hydrolytic DNA cleavage. Journal of American Chemical Society, 2011, 133(5): 20704-20707.

[38] BRANUM M E, TIPTON A K, ZHU SHOU-RONG, et al. Double-strand hydrolysis of plasmid DNA by dicerium complexes at $37{ }^{\circ} \mathrm{C}$. Journal of American Chemical Society, 2001, 123(9): 1898-1904.

[39] FABRIZIO M, LEONARD P, PAOLO P, et al. Hydrolytic metallonanozymes: from micelles and vesicles to gold nanoparticles. Molecules, 2016, 21(8): 1014.

[40] JENNINGS L K, STOREK K M, LEDVINA H E, et al. Pel is a cationic exopolysaccharide that cross-link extracellular DNA in the pseudomonas aeruginosa biofilm matrix. Proceeding of the National Academy of Science, 2015, 112(36): 11353-11358.

[41] SWARTIES J, DAS T, SHARIFI S, et al. A functional DNase I coating to prevent adhesion of bacteria and the formation of biofilm. Advanced Functional Materials, 2013, 23(22): 2843-2849.

[42] HU WEN-CHAO, YOUNIS M R, ZHOU YUE, et al. In situ fabrication of ultrasmall gold nanoparticles/2D MOFs hybrid as nanozyme for antibacterial therapy. Small, 2020, 16(23): 200553.

[43] XI JU-QUN, WEO GEN, AN LAN-FANG, et al. Copper/carbon hybrid nanozyme: tuning catalytic activity by the copper state for antibacterial therapy. Nano Letter, 2019, 19(11): 7645-7654.

[44] TAO YU, JU EN-GUO, REN JIN-SONG, et al. Bifunctionalized mesoporous silicasupported gold nanoparticles: intrinsic oxidase and peroxidase catalytic activities for antibacterial applications. Advanced Materials, 2015, 27(6): 1097-1104.

[45] SHAN JING-YANG, LI XIAO, YANG KAI-LI, et al. Efficient bacteria killing by $\mathrm{Cu}_{2} \mathrm{WS}_{4}$ nanocrystals with enzyme-like properties and bacteria-binding ability. ACS Nano, 2019, 13(12): 13797-13808.

[46] XU BO-LONG, WANG HUI, WANG WEI-WEI, et al. A single-atom nanozyme for wound disinfection applications. Angewandte Chemie International Edition, 2019, 58(15): 4911-4916.

[47] HUANG LIANG, CHEN JIN-XING, GAN LIN-FENG, et al. Single-atom nanozymes. Science Advances, 2019, 5(5): eaav5490.

[48] FANG GE, LI WEI-FENG, SHEN XIAO-MEI, et al. Differential Pd-nanocrystal facets demonstrate distinct antibacterial activity against gram-positive and gram-negative bacteria. Nature Communications, 2018, 9: 129 .

[49] NIU JING-SHENG, SUN YU-HUAN, WANG FA-MING, et al. Photomodulated nanozyme used for a Gram-selective antimicrobial. Chemistry of Materials, 2018, 30(20): 7027-7033.

[50] NATAN M, EDIN F, PERKAS N, et al. Two are better than one: combating $\mathrm{ZnO}$ and $\mathrm{MgF}_{2}$ nanoparticles reduces streptococcus penumoniae and staphylococcus aures biofilm formation on cochlear implants. Advanced Functional Materials, 2016, 26(15): 2473-2481.

[51] YIN WEN-YAN, YU JIE, LV FENG-TING, et al. Functionalized nano- $\mathrm{MoS}_{2}$ with peroxidase catalytic and near-infrared photothermal activities for safe and synergetic wound antibacterial applications. ACS Nano, 2016, 10(12): 11000-11011.

[52] JI HAI-WEI, DONG KAI, YAN ZHENG-QIN, et al. Bacterial hyaluronidase self-triggered prodrug release for chemo-photothermal synergistic treatment of bacterial infection. Small, 2016, 12(45): 6200-6206.

[53] ZOU XUE-FENG, ZHANG LI, WANG ZHAO-JUN, et al. Mechanisms of the antimicrobial activities of graphene material. J. Am. Chem. Soc., 2016, 138(7): 2064-2077.

[54] PERELSHTEIN I, LIPOVSKY A, PERKAS N, et al. The influence of the crystalline nature of nano-metal oxides on their antibacterial and toxicity properties. Nano Res., 2015, 8(2): 695-707.

[55] DICKINSON B C, CHANG CJ J. Chemistry and biology of reactive oxygen species in signaling or stress responses. Nat. Chem. Biol., 2011, 7(8): 504-511.

[56] WANG WAN-SHUN, LI BING-LIN, YANG HUI-LI, et al. Efficient elimination of multidrug-resistant bacteria using copper sulfide nanozymes anchored to graphene oxide nanosheets. Nano Res., 2020, 13(8): 2156-2164.

[57] LEVY S. Antibacterial resistance worldwide: causes, challenges and responses. Nature Medicine, 2004, 10(S12): S122-129.

[58] WU HONG, MOSER C, WANG HENG-ZHUANG, et al. Strategies for combating bacterial biofilm infections. International Journal of Oral Science, 2015, 1: 1-7.

[59] ARCIOLA C R, CAMPOCCIA D, SPEZIALE P, et al. Biofilm formation in staphylococcus implant infections: a review of molecular mechanisms and implications for biofilm-resistant materials. Biomaterials, 2012, 33(26): 5967-5982.

[60] LEBEAUX D, GHIGO J M, BELOIN C. Biofilm-related infections: bridging the gap between clinical management and fundamental 
aspects of recalcitrance toward antibiotics. Microbiology \& Molecular Biology Reviews, 2014, 78(3): 510-543.

[61] GAO LI-ZENG, GIGLIO K M, NELSON J L, et al. Ferromagnetic nanoparticles with peroxidase-like activity enhance the cleavage of biological macromolecules for biofilm elimination. Nanoscale, 2014, 6(5): 2588

[62] GAO LI-ZENG, LIU YUAN, KIM D, et al. Nanocatalysts promote streptococcus mutans biofilm matrix degradation and enhance bacterial killing to suppress dental caries in vivo. Biomaterials, 2016, 101: $272-284$.

[63] NAHA P C, LIU YUAN, HWANG G, et al. Dextran-coated iron oxide nanoparticles as biomimetic catalysts for localized and pH-activated biofilm disruption. ACS Nano, 2019, 13(5): 4960-4971.

[64] CHEN ZHAO-WEI, JI HAI-WEI, LIU CHAO-QUN, et al. A multinuclear metal complex based DNase-mimetic artificial enzyme: matrix cleavage for combating bacterial biofilms. Angewandte Chemie International Edition, 2016, 55(36): 10732-10736.

[65] LIU ZHENG-WEI, WANG FA-MING, REN JIN-SONG, et al. A series of MOF/Ce-based nanozymes with dual enzyme-like activity disrupting biofilms and hindering recolonization of bacteria. Biomaterials, 2019, 208: 21-31.

[66] LEJARS M, MARGAILlAN A, BRESSY C. Fouling release coatings: a nontoxic alternative to biocidal antifouling coatings. Chemical Reviews, 2012, 112(8): 4347-4390.

[67] GAO ZHI-GIANG, JIANG SHEN-MING, ZHANG QI-FU, et al.
Advances in research of marine antifouling fluorine resin coatings with low surface energy. Electroplating \& Finishing, 2017, 36(6): 273-279.

[68] 陈吉. 船舶纳米防污涂料的研究与应用. 武汉: 武汉大学硕士 学位论文, 2015 .

[69] NATALIO F, ANDRE R, HARTOG A F, et al. Vanadium pentoxide nanoparticles mimic vanadium haloperoxidases and thwart biofilm formation. Nature Nanotechnology, 2012, 7(8): 530-535.

[70] ANDRE R, NATALIO F, HUMANES M, et al. $\mathrm{V}_{2} \mathrm{O}_{5}$ nanowires with an intrinsic peroxidase-like activity. Advanced Functional Materials, 2011, 21(3): 501-509.

[71] ASSENM F L, LEVY S. A review of current toxicological concerns on vanadium pentoxide and other vnadium compounds: gaps in knowledge and directions for future research. Journal of Toxicology \& Environment, 2009, 12(4): 289-306.

[72] HERGET K, HUBACH P, PUSH S, et al. Haloperoxidase mimicry by $\mathrm{CeO}_{2-x}$ nanorods combats biofouling. Advanced Materials, 2017, 29(4): 1603823.

[73] HU MING-HAN, KORSCHELT K, VIEL MELANIE, et al. Nanozymes in nanofibrous mats with haloperoxidase-like activity to combat biofouling. ACS Applied Materia HOUUls \& Interfaces, 2018, 10(51): 44722-44730.

[74] ZHAO YU-YUN, TIAN YUE, CUI YAN, et al. Small molecule-capped gold nanoparticles as potent antibacterial agents that target Gramnegative bacterial. J. Am. Chem. Soc, 2010, 132(35): 12349- 12356. 